\title{
Association between in-hospital adverse events and mortality for patients with brain tumors
}

\author{
*Miriam Nuño, PhD, Christine Carico, BS, Debraj Mukherjee, MD, MPH, Diana Ly, MPH, \\ Alicia Ortega, BA, Keith L. Black, MD, and Chirag G. Patil, MD \\ Center for Neurosurgical Outcomes Research, Maxine Dunitz Neurosurgical Institute, Department of Neurosurgery, \\ Cedars-Sinai Medical Center, Los Angeles, California
}

\begin{abstract}
OBJECT The Agency for Healthcare Research and Quality patient safety indicators (PSIs) and the Centers for Medicare and Medicaid Services hospital-acquired conditions (HACs) are administrative data-based metrics. The use of these outcomes as standard performance measures has been discussed in previous studies. With the objective of determining the applicability of these events as performance metrics among patients undergoing brain tumor surgery, this study had 2 aims: 1) to evaluate the association between PSIs, HACs, and in-hospital mortality rates; and 2) to determine a correlation between hospital volume, PSIs, and HACs.
\end{abstract}

METHODS Patients with brain tumors treated between 1998 and 2009 were captured in the Nationwide Inpatient Sample database. Hospitals were categorized into groups according to surgical volume. Associations between PSIs, HACs, and in-hospital mortality rates were studied. Factors associated with a PSI, HAC, and mortality were evaluated in a multivariate setting.

RESULTS A total of 444,751 patients with brain tumors underwent surgery in 1311 hospitals nationwide. Of these, $7.4 \%$ of patients experienced a PSI, $0.4 \%$ an HAC, and $1.9 \%$ died during their hospitalization. The occurrence of a PSI was strongly associated with mortality. Patients were 7.6 times more likely to die (adjusted odds ratio [aOR] 7.6, $\mathrm{Cl}$ 6.7-8.7) with the occurrence of a PSI in a multivariate analysis. Moderate to strong associations were found between HACs, PSIs, and hospital volume. Patients treated at the highest-volume hospitals compared with the lowest-volume ones had reduced odds of a PSI (aOR 0.9, $\mathrm{Cl} 0.8-1.0)$ and HAC (aOR 0.5, Cl 0.5-0.08).

CONCLUSIONS Patient safety-related adverse events were strongly associated with in-hospital mortality. Moderate to strong correlations were found between PSIs, HACs, and hospital procedural volume. Patients treated at the highestvolume hospitals had consistently lower rates of mortality, PSIs, and HACs compared with those treated at the lowestvolume facilities.

http://thejns.org/doi/abs/10.3171/2014.10.JNS141516

KEY WORDS patient safety indicators; hospital-acquired conditions; in-hospital mortality; hospital procedural volume; oncology

I $\mathrm{N}$ an effort to improve patient safety, systems and measures have been proposed by the Agency for Healthcare Research and Quality (AHRQ) since the early 1990s. The patient safety indicators (PSIs), developed by the AHRQ and revised by the University of California at San Francisco-Stanford University Evidence-based Practice Center (UCSF-Stanford EPC), are a set of administrative data-based metrics used to identify potential in-hospital patient safety events. ${ }^{1}$ Furthermore, the Centers for
Medicare and Medicaid Services (CMS) proposed a set of hospital-acquired conditions (HACs) that are used to guide reimbursement penalties as part of a pay-for-performance program..$^{10}$ Postoperative events such as pulmonary embolism (PE) or deep venous thrombosis (DVT), respiratory failure, and hemorrhage/hematoma are among some of the PSIs proposed by the AHRQ. Catheter-associated urinary tract infections (UTIs), falls, and trauma are part of the CMS list of HACs. The PSIs focus on potentially prevent-

ABBREVIATIONS AHRQ = Agency for Healthcare Research and Quality; aOR = adjusted odds ratio; $\mathrm{CCI}=\mathrm{Charlson}$ Comorbidity Index; $\mathrm{CMS}=\mathrm{Centers} \mathrm{for} \mathrm{Medicare}$ and Medicaid Services; DVT = deep venous thrombosis; HAC = hospital-acquired condition; IQR = interquartile range; NIS = Nationwide Inpatient Sample; PE = pulmonary embolism; PSI = patient safety indicator; UCSF-Stanford EPC = University of California at San Francisco-Stanford University Evidence-based Practice Center; UTI = urinary tract infection; V1-V4 = lowest- to highest-volume hospitals.

SUBMITTED July 1, 2014. ACCEPTED October 31, 2014

INCLUDE WHEN CITING Published online May 22, 2015; DOI: 10.3171/2014.10.JNS141516.

DISCLOSURE Dr. Patil is a consultant for Cell Works, Inc.

* Dr. Nuño and Ms. Carico contributed equally to this work. 
able instances of complications, whereas the HACs represent an undesirable condition arising during a hospital stay. It is worth noting that some of these indicators do not specifically measure a patient's outcome or the standard of care provided. Rather, they measure an aspect of care that is correlated with measures of quality or patient outcomes.

Because performance outcomes continue to be important factors for patients and hospitals as well as health care providers, newly proposed metrics such as PSIs and HACs need to be evaluated in specific clinical domains. Numerous outcomes have been considered to evaluate hospital performance. Some of these metrics include in-hospital mortality, 30-day readmissions, in-hospital length of stay, and complications, to name a few. $5,8,18,19,21,25,32,35,37$ These outcomes have been evaluated in association with hospital procedural volume. An established association suggests that patients treated at higher-volume hospitals have a tendency to attain outcomes that are superior to those reported for patients treated at these hospitals' lower-volume counterparts. In this study, we evaluate the occurrence of safety-related adverse events (i.e., PSIs) and HACs for patients with brain tumor who underwent a craniotomy. Our study aims first to evaluate the association between PSIs, HACs, and in-hospital mortality rates, and second to assess any association between hospital volume, PSIs, and HACs. We anticipate that a confirmed association between PSIs, HACs, and mortality rates may motivate efforts to prevent or reduce the occurrence of these events, with the focus on improving in-hospital mortality. Similarly, establishing a correlation between hospital volume, PSIs, and HACs may support the use of these metrics as hospital performance measures in this patient population.

\section{Methods}

\section{Data Source and Cohort Selection}

We used the Nationwide Inpatient Sample (NIS) database to capture patients with brain tumor who had been surgically treated in US hospitals between 1998 and 2009. Data were obtained from the Healthcare Cost and Utilization Project of the AHRQ. ${ }^{2}$ The NIS collects data for a stratified random sampling (20\%) of hospitals that are representative of the American medical community. Using International Classification of Diseases, Ninth Revision, Clinical Modification (ICD-9-CM) codes, we identified adult patients (18 years of age or older) with a primary diagnosis of acoustic neuroma (ICD-9-CM: 225.1), meningioma (ICD-9-CM: 225.2), and malignant tumor (ICD9-CM: 191.0-191.9, 192.0, 192.1, 194.3, 194.4, 198.3) of the brain; only patients who underwent either a biopsy (ICD-9-CM: 1.11-1.15, 1.18, 1.19) or a craniotomy (ICD9-CM: $1.23-1.25,1.31,1.32,1.39,1.51-1.53,1.59,1.60)$ were included (Table 1). The primary diagnosis code is the principal condition requiring admission for treatment, as determined by the admitting physician. ${ }^{13}$

\section{Patient and Hospital Characteristics}

A patient's age, sex, preexisting medical conditions (Charlson Comorbidity Index [CCI]), ${ }^{11}$ and hospital characteristics such as teaching status, hospital bed size, and hospital surgical volume were documented. Hospitals
TABLE 1. The ICD-9-CM codes for diagnoses, procedures, and HACs

\begin{tabular}{|c|c|}
\hline Factor & ICD-9-CM Code \\
\hline \multicolumn{2}{|l|}{ Primary diagnosis } \\
\hline Acoustic neuroma & 225.1 \\
\hline Meningioma & 225.2 \\
\hline Malignant brain tumor & $\begin{array}{l}\text { 191.0-191.9, 192.0 } \\
\text { 192.1, 194.3, 194.4, } \\
198.3\end{array}$ \\
\hline \multicolumn{2}{|l|}{ Surgical procedure } \\
\hline Biopsy & $1.11-1.15,1.18,1.19$ \\
\hline Craniotomy & $\begin{array}{c}1.23-1.25,1.31,1.32 \\
1.39,1.51-1.53 \\
1.59,1.60\end{array}$ \\
\hline \multicolumn{2}{|l|}{ HAC } \\
\hline Foreign object retained after surgery & $998.4,998.7$ \\
\hline Air embolism & 999.1 \\
\hline \multicolumn{2}{|l|}{ Falls \& trauma } \\
\hline Fracture & $800-829$ \\
\hline Dislocation & $830-839$ \\
\hline Intracranial injury & $850-854$ \\
\hline Crushing injury & $925-929$ \\
\hline Burn & $940-949$ \\
\hline Other injuries & $991-994$ \\
\hline Catheter-associated UTI & 996.64 \\
\hline Vascular catheter-associated infection & $999.31,999.32,999.33$ \\
\hline \multicolumn{2}{|l|}{ Manifestations of poor glycemic control } \\
\hline Diabetic ketoacidosis & $250.10-250.13$ \\
\hline Nonketotic hyperosmolar coma & $250.20-250.23$ \\
\hline Hypoglycemic coma & 251.0 \\
\hline Secondary diabetes w/ ketoacidosis & $249.10-249.11$ \\
\hline Secondary diabetes w/ hyperosmolarity & $249.20-249.21$ \\
\hline
\end{tabular}

were classified into 1 of 4 cohorts (V1-V4) according to yearly surgical volume. The lowest-volume hospitals were designated by V1, whereas the highest-volume ones were referred to as V4 hospitals. The average number of procedures per year conducted in V1 hospitals ranged from 0 to 15 , it was 16-50 among V2 hospitals, 51-100 for V3 hospitals, and 101 or more for hospitals designated by V4. Categorization of hospital cohorts according to procedural volume was reached based on volume thresholds that were deemed clinically relevant by neurosurgeons in our team (C.G.P., D.M.). It is worth noting that hospital volume was first evaluated as a continuous variable, and the findings were consistent with our results obtained using multiple categories. Data were missing for sex in 1410 $(0.32 \%)$ patients, for race in $109,699(24.7 \%)$, for income in $11,477(2.6 \%)$, and for hospital teaching status and bed size in $1198(0.30 \%)$.

\section{Outcomes of Interest}

Complications, as captured by PSIs, HACs, and inhospital mortality, were the main outcomes of interest in 
this study. Hospital procedural volume was a secondary outcome. The PSIs evaluated included the following: 1) decubitus ulcer; 2) iatrogenic pneumothorax; 3) central venous catheter-related bloodstream infections; 4) postoperative hip fracture; 5) postoperative hemorrhage or hematoma; 6) postoperative physiological and metabolic derangement; 7) postoperative respiratory failure; 8) postoperative PE or DVT; 9) postoperative sepsis; 10) postoperative wound dehiscence; and 11) accidental puncture or laceration during a procedure or medical care (Table 2). A variable describing the number of days from admission to secondary procedures was used to confirm that all PSIs resulting from postsurgical procedures occurred within the index hospitalization of interest. The HACs considered were as follows: 1) foreign object retained after surgery; 2) air embolism; 3) falls and trauma; 4) catheter-associated UTI; 5) vascular catheter-associated infection; 6) manifestations of poor glycemic control; 7) diabetic ketoacidosis; 8) nonketotic hyperosmolar coma; 9) hypoglycemic coma; 10) secondary diabetes with ketoacidosis; and 11) secondary diabetes with hyperosmolarity.

\section{Statistical Analysis}

Descriptive statistics were used to summarize patient and hospital characteristics. A multivariate logistic regression model that adjusted for patient and hospital factors evaluated associations with PSI, HAC, and postprocedural mortality outcomes. Separate models were used to evaluate each of these outcomes (mortality, HAC, PSI). Adjustments were made for a patient's race and income, and these factors were found to have no additional predictive value or association in these predictive models. Chi-square and Student t-tests were used to evaluate differences in mortality rates for PSI versus non-PSI and HAC versus non-HAC cohorts as a function of hospital volume. Adjusted odds ratio (aOR), 95\% CI, interquartile range (IQR), and corresponding $\mathrm{p}$ values were reported. Nationwide estimates were derived using the SAS PROC SURVEY methodology. All analysis used SAS version 9.1 for Windows (SAS Institute, Inc.).

\section{Results \\ Demographic Data}

According to the NIS database, 444,751 patients underwent brain tumor surgery at 1311 US hospitals between 1998 and 2009. The median patient age was 57 years (IQR 46-68 years) with a female preponderance (52.6\%), and a significant portion $(47.3 \%)$ of patients who had 2 or more preexisting conditions (Table 3). Most patients were treated at teaching hospitals (76.3\%). A significant fraction of patients underwent a craniotomy $(87.2 \%)$ compared with biopsy (12.8\%). Among the 1311 hospitals, 760 fell within the V1 cohort (lowest volume), 409 were in the V2 cohort, 86 in the V3 cohort, and the remaining 56 hospitals were placed among the highest-volume cohort (V4). In a univariate setting, the highest-volume hospitals compared with the lowest-volume ones had younger patients (54 vs 61 years, $p$ $<0.0001)$, fewer females $(51.7 \%$ vs $53.0 \%, \mathrm{p}=0.03)$, fewer comorbidities $(40.9 \%$ vs $55.0 \%, \mathrm{p}<0.0001)$, and higher rates of craniotomy $(89.4 \%$ vs $85.8 \%, \mathrm{p}<0.0001)$.
TABLE 2. The ICD-9-CM codes for PSIs

\begin{tabular}{|c|c|}
\hline PSI & ICD-9-CM Code \\
\hline Pressure ulcer & $\begin{array}{l}707.0-707.07,707.09,707.23, \\
\quad 707.24,707.25\end{array}$ \\
\hline latrogenic pneumothorax & 512.1 \\
\hline $\begin{array}{l}\text { Central venous catheter-related } \\
\text { bloodstream infections }\end{array}$ & $\begin{array}{l}996.62,999.3,999.31 \\
999.32\end{array}$ \\
\hline Postop hip fracture & $\begin{array}{l}820.00-820.03,820.09- \\
820.13,820.19-820.22 \\
820.30-820.32,820.8 \\
820.9\end{array}$ \\
\hline Postop hemorrhage or hematoma & $\begin{array}{l}998.11,998.12,287, \\
\quad 388.0-388.9,394.1,399.8 \\
499.5,579.3,609.4,180.9 \\
\quad 540,541.2,591.9,610 \\
\quad 699.8,701.4,710.9,759.1 \\
\quad 759.2,860.4\end{array}$ \\
\hline $\begin{array}{l}\text { Postop physiological \& metabolic } \\
\text { derangement }\end{array}$ & $\begin{array}{l}\text { 249.10, 249.11, 249.20, } \\
\text { 249.21, 249.30, 249.31, } \\
\text { 250.10-250.13, 250.20- } \\
\text { 250.23, 250.30-250.33, } \\
\text { 584.5-584.9, 586, 997.5, } \\
399.5,549.8\end{array}$ \\
\hline Postop respiratory failure & $\begin{array}{l}\text { 518.51, 518.53, 518.81, } \\
518.84,967.0-967.2,960.4\end{array}$ \\
\hline Postop PE or DVT & $\begin{array}{l}451.11,451.19,451.2,451.81 \\
451.9,453.40-453.42 \\
453.8,453.9,415.1,415.11 \\
415.13,415.19\end{array}$ \\
\hline Postop sepsis & $\begin{array}{l}\text { 038.0, 038.1, 038.10, 038.11, } \\
\text { 038.12, 038.19, 038.2, } \\
\text { 038.3, 785.52, 785.59, } \\
\text { 998.0, 998.00, 998.02, } \\
\text { 038.40-038.44, 038.49, } \\
\text { 038.8, 038.9, 995.91, } \\
\text { 995.92 }\end{array}$ \\
\hline Postop wound dehiscence & 546.1 \\
\hline $\begin{array}{l}\text { Accidental puncture or laceration dur- } \\
\text { ing procedure or medical care }\end{array}$ & E870.0-E870.9, 998.2 \\
\hline
\end{tabular}

\section{Associations Among PSIs, HACs, and Mortality Rates}

Although the overall mortality rate was $1.9 \%$, this rate increased to $11.8 \%$ (5.2-fold) with the occurrence of a PSI, and to $4.3 \%$ (1.3-fold) with an HAC. The strong association between a PSI and mortality was independent of hospital volume. Univariate analysis showed that the mortality rate of patients who experienced a PSI was $15.3 \%$ if treated at the lowest-volume (V1) hospitals compared with the $8.8 \%$ rate captured among highest-volume (V4) facilities ( $\mathrm{p}<$ 0.0001, Fig. 1). While HACs were consistently associated with higher mortality rates, this finding was particularly significant $(\mathrm{p}=0.003)$ if patients received treatment at $\mathrm{V} 1$ hospitals (Fig. 2).

In a multivariate model that adjusted for a patient's age, sex, preexisting comorbidities, and hospital volume, among other factors, we found that the occurrence of a PSI 
TABLE 3. Patient and hospital characteristics of adult patients who underwent resection for brain tumor in US hospitals between 1998 and 2009*

\begin{tabular}{|c|c|c|c|c|c|c|}
\hline \multirow[b]{2}{*}{ Variable } & \multirow[b]{2}{*}{ All Patients } & \multicolumn{4}{|c|}{ Hospitals by No. of Procedures per $\mathrm{Yr}$} & \multirow[b]{2}{*}{$\mathrm{p}$ Value } \\
\hline & & V1 & V2 & V3 & V4 & \\
\hline No. of patients & 444,751 & 61,808 & 162,819 & 85,448 & 134,676 & \\
\hline No. of hospitals & 1311 & 760 & 409 & 86 & 56 & \\
\hline Age at admission in yrs & & & & & & $<0.0001$ \\
\hline Mean & 57.1 & 59.9 & 58.6 & 56.4 & 54.4 & \\
\hline Median (IQR) & $57(46-68)$ & $61(49-71)$ & $59(48-69)$ & $56(46-67)$ & $54(43-65)$ & \\
\hline Sex† & & & & & & 0.03 \\
\hline Male & $210,089(47.4)$ & $28,992(47.0)$ & $76,307(46.9)$ & $40,065(47.1)$ & $64,725(48.3)$ & \\
\hline Female & $233,253(52.6)$ & $32,728(53.0)$ & $86,258(53.1)$ & $45,016(52.9)$ & $69,251(51.7)$ & \\
\hline Race† & & & & & & 0.04 \\
\hline White & $269,492(80.4)$ & $36,656(74.6)$ & $95,626(81.1)$ & $50,078(81.2)$ & $87,132(81.9)$ & \\
\hline Nonwhite & $65,560(19.6)$ & $12,451(23.4)$ & $22,323(18.9)$ & $11,557(18.8)$ & $19,229(18.1)$ & \\
\hline Median income $†$ & & & & & & 0.0008 \\
\hline$\$ 1-\$ 38,999$ & $102,444(23.6)$ & $16,731(27.8)$ & $39,183(24.6)$ & $19,924(23.9)$ & $26,606(20.4)$ & \\
\hline$\$ 39,000-\$ 47,999$ & $111,695(25.8)$ & $16,166(26.9)$ & $43,157(27.1)$ & $22,669(27.2)$ & $29,703(22.7)$ & \\
\hline$\$ 48,000+$ & $219,136(50.6)$ & $27,270(45.3)$ & $76,629(48.2)$ & $40,867(49.0)$ & $74,371(56.9)$ & \\
\hline $\mathrm{CCl}$ & & & & & & $<0.0001$ \\
\hline $0-1$ & $234,514(52.7)$ & $27,827(45.0)$ & $81,464(50.0)$ & $45,656(53.4)$ & 79,567 (59.1) & \\
\hline $2+$ & $210,237(47.3)$ & $33,981(55.0)$ & $81,355(50.0)$ & $39,792(46.6)$ & $55,109(40.9)$ & \\
\hline Tumor type & & & & & & 0.75 \\
\hline Benign & $121,481(27.3)$ & $16,914(27.4)$ & 44,105 (27.1) & $24,093(28.2)$ & $36,369(27.0)$ & \\
\hline Malignant & $323,271(72.7)$ & $44,894(72.6)$ & $118,715(72.9)$ & $61,356(71.8)$ & $98,306(73.0)$ & \\
\hline Teaching hospital† & & & & & & $<0.0001$ \\
\hline No & $104,994(23.7)$ & $38,043(61.8)$ & $59,813(36.8)$ & $5,708(6.7)$ & $1,430(1.1)$ & \\
\hline Yes & $338,559(76.3)$ & $23,547(38.2)$ & $102,704(63.2)$ & $79,062(93.3)$ & $133,246(98.9)$ & \\
\hline Procedure & & & & & & $<0.0001$ \\
\hline Craniotomy & $387,956(87.2)$ & $53,046(85.8)$ & $140,527(86.3)$ & $74,008(86.6)$ & $120,374(89.4)$ & \\
\hline Biopsy & $56,796(12.8)$ & $8,762(14.2)$ & $22,292(13.7)$ & $11,440(13.4)$ & $14,302(10.6)$ & \\
\hline
\end{tabular}

$\mathrm{V} 1=$ hospitals averaged $0-15$ procedures per year; $\mathrm{V} 2=$ hospitals averaged $16-50$ procedures per year; $\mathrm{V} 3=$ hospitals averaged $51-100$ procedures per year; $\mathrm{V} 4=$ hospitals averaged 101-420 procedures per year ( 1 1 = lowest volume; $\mathrm{V} 4=$ highest volume).

* Unless otherwise indicated, values are given as the number (\%).

$\dagger$ In the categories in which data are missing, the percentages are calculated based on the number of cases reported in that category, not the overall total.

was strongly associated with death (Table 4). Patients who experienced a PSI were 7.6 times more likely to die during their hospitalization (aOR 7.6, CI 6.7-8.7). The occurrence of an HAC did not impact the odds of death in this cohort (aOR 1.0, CI 0.6-1.9).

Other factors shown to be marginally associated with increased odds of death included a patient's age (aOR 1.2, CI 1.1-1.2), more preexisting comorbidities (aOR 1.2, CI 1.1-1.2), and longer hospital stays (aOR 1.1, CI 1.1-1.1). Female sex was mildly associated with a reduction in the odds of death (aOR 0.9, CI 1.0-1.6).

\section{Associations Among PSIs, HACs, and Hospital Volume}

We found that $7.4 \%$ of patients contracted a PSI, and $0.4 \%$ experienced an HAC (Table 5). The most common adverse events in our cohort were postoperative PE or DVT (2.3\%), postoperative respiratory failure (1.8\%), and postoperative hemorrhage or hematoma (1.5\%), statistics that are mirrored in previous studies focusing on alternate patient cohorts. ${ }^{17,34}$ In the univariate analysis, the lowest-volume hospitals had significantly higher rates of PSIs $(8.7 \%$ vs $7.2 \%, \mathrm{p}=0.01)$ and HACs $(0.7 \%$ vs $0.3 \%, \mathrm{p}$ $<0.0001)$ than the highest-volume hospitals. The overall mortality rate was $1.9 \%$, with a decreasing trend that persisted as hospital volume increased ( $\mathrm{p}<0.0001)$.

After adjusting for patient and hospital confounders, we found that hospital volume was marginally associated with the occurrence of a PSI (Table 6). Patients who were treated at the highest-volume hospitals (V4) compared with the lowest-volume ones (V1) had a $10 \%$ reduction in the odds of a PSI (aOR 0.9, CI 0.8-1.0). A stronger association between hospital volume and HAC was documented (Table 7). Patients treated at the highest-volume hospitals compared with the lowest-volume ones had a $50 \%$ reduction in the odds of experiencing an HAC (aOR 0.5, CI 0.3-0.8). The decreasing odds of an HAC were consistently observed among patients treated at V2 (aOR 0.7, CI 0.5-0.9) and V3 (aOR 0.6, CI 0.4-0.9) hospitals. 


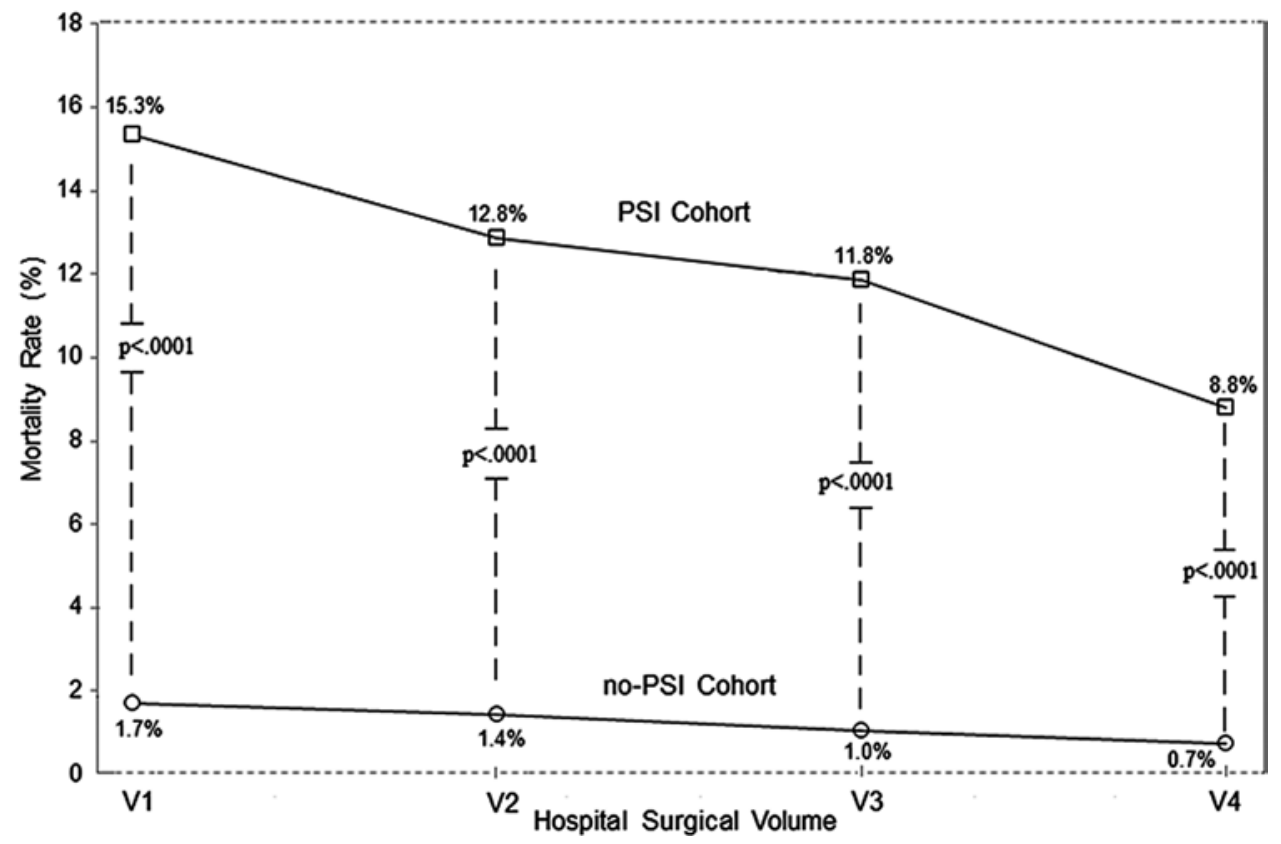

FIG. 1. Graph showing mortality rate by hospital surgical volume according to whether patients experienced an adverse event (i.e., PSI) during their hospitalization.

\section{Discussion}

Patients with brain tumors undergoing a craniotomy were found to experience a safety-related adverse event (i.e., PSI) at a rate of 7.4\%. Significantly fewer patients $(0.4 \%)$ contracted a HAC. Postoperative PE or DVT, followed by respiratory failure and hemorrhage/hematoma accounted for the majority of the adverse events. The PSI rates documented in our cohort were significantly lower than previously reported for patients with ruptured ${ }^{16}$ and unruptured ${ }^{17}$ brain aneurysms. In these studies, Fargen et al. aimed to establish PSIs and HACs as standard performance measures in patients with ruptured and unruptured aneurysms. They showed that the occurrence of a PSI or HAC was associated with longer hospital stays, higher charges, and greater in-hospital mortality rates in both ruptured and unruptured aneurysm cohorts. The occur-

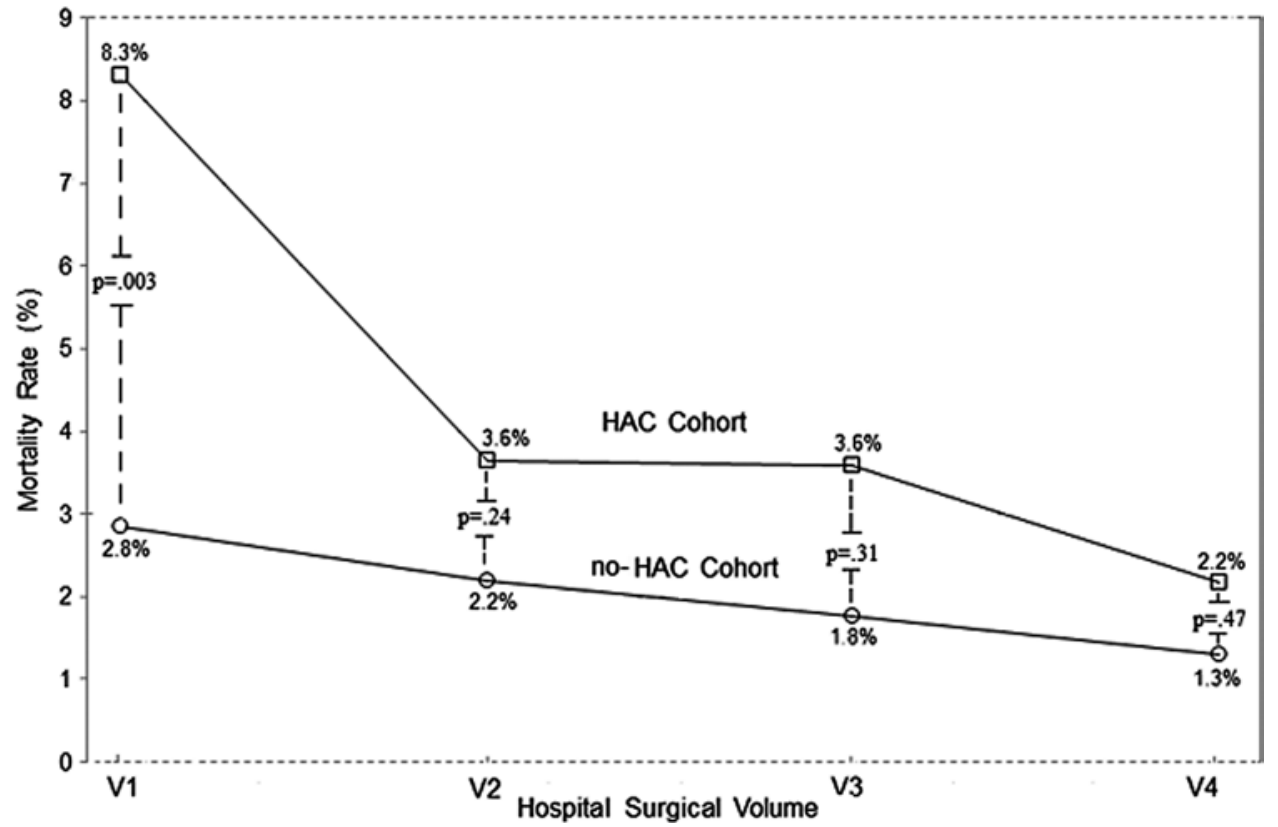

FIG. 2. Graph showing mortality rate by hospital surgical volume according to whether patients experienced an HAC during their hospitalization. 
TABLE 4. The aOR and $95 \% \mathrm{Cl}$ for factors associated with mortality*

\begin{tabular}{lccc}
\hline \multicolumn{1}{c}{ Variable } & aOR & $95 \%$ Cl† & p Value \\
\hline Greater age in decade increments & 1.2 & $1.1-1.2$ & $<0.0001$ \\
\hline Sex (ref: male) & & & \\
\hline Female & 0.9 & $1.0-1.6$ & 0.03 \\
\hline CCl, per increment & 1.2 & $1.1-1.2$ & $<0.0001$ \\
\hline Tumor type (ref: benign) & & & \\
\hline$\quad$ Malignant & 1.4 & $1.2-1.6$ & 0.28 \\
\hline Teaching hospital (ref: no) & & & \\
\hline Yes & 1.0 & $0.9-1.2$ & 0.89 \\
\hline Hospital bed size (ref: large) & & & \\
\hline Small & 0.7 & $0.5-0.9$ & 0.39 \\
\hline Medium & 1.0 & $0.9-1.1$ & 0.24 \\
\hline Hospital vol (ref: V1 [lowest vol]) & & & \\
\hline V2 & 0.8 & $0.7-0.9$ & 0.006 \\
\hline V3 & 0.7 & $0.6-0.9$ & $<0.0001$ \\
\hline V4 (highest vol) & 0.5 & $0.4-0.7$ & $<0.0001$ \\
\hline Mean LOS in days & 1.1 & $1.1-1.1$ & $<0.0001$ \\
\hline Occurrence of a PSI (ref: no) & & & \\
\hline Yes & 7.6 & $6.7-8.7$ & $<0.0001$ \\
\hline LOS & & &
\end{tabular}

LOS = length of hospital stay; ref = reference value.

* The occurrence of a PSI, race, and income were nonsignificant predictors of mortality.

$\dagger$ Estimates in the Cls were rounded up and therefore may include 1.0 even when $p \leq 0.05$.

rence of a PSI was strongly associated with in-hospital mortality. Similar to these previous studies, we found that patients who experienced a PSI were 7.6 times more likely to die during their hospitalization that those who did not. This effect of a PSI on mortality is comparable to the 7to 8-fold increase reported in patients with ruptured subarachnoid hemorrhage. ${ }^{16}$

Additionally, our multivariate model demonstrated a significant protective effect of malignant lesions against the development of a PSI. Although this initially appears counterintuitive, given the limitations of a national database as well as the treatment and surgical factors involving these benign histological types (meningioma and vestibular schwannoma), this result is logically explicable. Meningiomas are often large tumors by the time patients undergo surgical intervention, thereby necessitating longer operating times and predisposing patients to postoperative events such as venous thromboembolisms and infectious complications. ${ }^{28}$ In accordance with these considerations, 2 recent studies have reported a higher incidence of postoperative complications (namely hematoma and surgical site infection) in patients with meningioma as opposed to other intrinsic tumors, such as gliomas. ${ }^{25,33}$ Furthermore, postoperative meningitis is a well-known complication following skull base surgery, such as that for treatment of vestibular schwannoma. ${ }^{6,12}$ In a study by Darrouzet et al., tumor size was a significant predictor of the development of meningitis postoperatively. ${ }^{12}$ Furthermore, although tumor size and location are important confounding factors, we did not have access to these variables, and thus were unable to adjust for them in our multivariate model to evaluate these hypotheses.

In our bivariate evaluation of the correlation between PSIs, HACs, and hospital procedural volume, we found a strong association between HACs and volume; PSIs had a moderate correlation with hospital volume. Patients treated at the highest-volume hospitals were $50 \%$ less likely to experience an HAC compared with those treated at the lowest-volume facilities. Similarly, patients treated at the highest-volume hospitals experienced a $10 \%$ reduction in the odds of experiencing a safety-related adverse event.

Since the early work of Luft et al. demonstrating a relationship between operative volume and surgical outcomes, ${ }^{27}$ numerous studies have explored similar correlations for several patient populations. Recent research supports an association between 30-day readmissions and procedural volume. ${ }^{8,18,19,21,35,37}$ Tsai et al., showed that hospitals with high surgical volume and low surgical mor-

TABLE 5. Rates of mortality, PSIs, and HACs among adult patients with brain tumors who underwent resection in US hospitals between 1998 and 2009*

\begin{tabular}{|c|c|c|c|c|c|c|}
\hline \multirow[b]{2}{*}{ Variable } & \multirow[b]{2}{*}{ Overall Rate } & \multicolumn{4}{|c|}{ Hospitals by No. of Procedures per $\mathrm{Yr}$} & \multirow[b]{2}{*}{$p$ Value } \\
\hline & & V1 & V2 & V3 & V4 & \\
\hline \multicolumn{7}{|l|}{ PSIs (\%) } \\
\hline Any & 7.4 & 8.7 & 7.1 & 7.1 & 7.2 & 0.01 \\
\hline Postop hemorrhage/hematoma & 1.5 & 1.7 & 1.4 & 1.5 & 1.4 & 0.58 \\
\hline Postop physiologic/metabolic derangement & 1.2 & 1.5 & 1.3 & 1.0 & 1.0 & 0.0002 \\
\hline Postop respiratory failure & 1.8 & 2.9 & 2.0 & 1.6 & 1.2 & $<0.0001$ \\
\hline Postop PE or DVT & 2.3 & 1.9 & 1.8 & 2.4 & 3.0 & $<0.0001$ \\
\hline Postop sepsis & 0.7 & 1.0 & 0.7 & 0.6 & 0.5 & $<0.0001$ \\
\hline Accidental puncture or laceration & 0.4 & 0.3 & 0.3 & 0.4 & 0.5 & 0.53 \\
\hline \multicolumn{7}{|l|}{ HACs (\%) } \\
\hline Any & 0.4 & 0.7 & 0.4 & 0.3 & 0.3 & $<0.0001$ \\
\hline In-hospital mortality rate (\%) & 1.9 & 2.9 & 2.2 & 1.8 & 1.3 & $<0.0001$ \\
\hline
\end{tabular}

* Subsets of the most common PSIs are described. 
TABLE 6 . The aOR and $95 \% \mathrm{Cl}$ for factors associated with the occurrence of a PSI ${ }^{*}$

\begin{tabular}{|c|c|c|c|}
\hline Variable & $\mathrm{aOR}$ & $95 \% \mathrm{Cl} \dagger$ & p Value \\
\hline Greater age in decade increments & 1.1 & $1.1-1.1$ & $<0.0001$ \\
\hline \multicolumn{4}{|l|}{ Sex (ref: male) } \\
\hline Female & 0.8 & $0.8-0.9$ & $<0.0001$ \\
\hline $\mathrm{CCl}$, per increment & 1.2 & $1.2-1.2$ & $<0.0001$ \\
\hline \multicolumn{4}{|l|}{ Tumor type (ref: benign) } \\
\hline Malignant & 0.7 & $0.7-0.8$ & $<0.0001$ \\
\hline \multicolumn{4}{|l|}{ Teaching hospital (ref: no) } \\
\hline Yes & 0.9 & $0.8-1.0$ & 0.05 \\
\hline \multicolumn{4}{|l|}{ Hospital bed size (ref: large) } \\
\hline Small & 1.0 & $0.8-1.2$ & 0.90 \\
\hline Medium & 1.1 & $1.0-1.2$ & 0.10 \\
\hline \multicolumn{4}{|l|}{$\begin{array}{l}\text { Hospital surgical vol (ref: V1 [lowest } \\
\text { vol]) }\end{array}$} \\
\hline V2 & 0.9 & $0.8-1.0$ & 0.21 \\
\hline V3 & 0.9 & $0.7-1.0$ & 0.03 \\
\hline V4 (highest vol) & 0.9 & $0.8-1.0$ & 0.04 \\
\hline Mean LOS in days & 1.2 & $1.2-1.3$ & $<0.0001$ \\
\hline
\end{tabular}

tality had lower rates of surgical readmission than other hospitals. ${ }^{37}$ Further studies have also reported a strong association between complications and volume.,22,32 With respect to PSIs and HACs, ours is one of the first studies to establish a correlation between these metrics and procedural volume for any patient population. In a smallersample-size study (2002-2009), Zacharia et al. showed higher rates of HACs in higher-volume centers. ${ }^{38}$

We found that the highest-volume hospitals had fewer PSIs and HACs than the lowest-volume ones. Even after adjusting for factors such as a patient's age, preexisting conditions, and tumor type, among others, superior outcomes (lowest rates of mortality, PSIs, and HACs) among high-volume hospitals persisted. Differences in our results from Zacharia et al.'s study of HACs may be partially explained by the fact that they included DVT/PE as part of the HACs, whereas we did not. However, more important may be the fact that they dichotomized hospital volume into 2 categories ( $\leq 50$ and $>50$ cases per year), whereas we opted for more stratifications. Although it is difficult to discern the factors driving this volume-outcome trend, it is possible that greater awareness in protecting patients from postoperative complications, as previously noted, may in part provide a reasonable explanation for this relationship. ${ }^{7,20}$ More experienced neurosurgeons, ancillary personnel, and advanced imaging technology available at high-volume hospitals may also account for the improved short-term outcomes.

Despite numerous efforts to provide equal access to health care, studies continue to highlight disparities in the management of this disease in adult and pediatric pa-
TABLE 7. The aOR and $95 \% \mathrm{Cl}$ for factors associated with the occurrence of an HAC*

\begin{tabular}{lccc}
\hline \multicolumn{1}{c}{ Variable } & aOR & $95 \%$ Cl† & p Value \\
\hline Greater age in decade increments & 1.2 & $1.1-1.3$ & 0.0002 \\
\hline Sex (ref: male) & & & \\
\hline$\quad$ Female & 1.3 & $1.0-1.6$ & 0.03 \\
\hline CCl, per increment & 1.3 & $1.2-1.4$ & $<0.0001$ \\
\hline Tumor type (ref: benign) & & & \\
\hline$\quad$ Malignant & 0.9 & $0.7-1.1$ & 0.28 \\
\hline Teaching hospital (ref: no) & & & \\
\hline Yes & 0.9 & $0.7-1.3$ & 0.89 \\
\hline Hospital bed size (ref: large) & & & \\
\hline Small & 0.7 & $0.4-1.2$ & 0.39 \\
\hline Medium & 0.8 & $0.6-1.1$ & 0.24 \\
\hline Hospital vol (ref: V1 [lowest vol]) & & & \\
\hline V2 & 0.7 & $0.5-0.9$ & 0.03 \\
\hline V3 & 0.6 & $0.4-0.9$ & 0.003 \\
\hline V4 (highest vol) & 0.5 & $0.3-0.8$ & 0.02 \\
\hline Mean LOS in days & 1.1 & $1.1-1.1$ & $<0.0001$ \\
\hline
\end{tabular}

* The occurrence of a PSI, race, and income were nonsignificant predictors of an HAC.

† Estimates in the Cls were rounded up and therefore may include 1.0 even when $p \leq 0.05$.

tients..$^{15,26,30,31}$ In their 2010 study, Mukherjee et al. showed that Hispanic children in whom a brain tumor was diagnosed were less likely to receive high-quality treatment at specialized neurosurgery hospitals than other children with the same condition. ${ }^{31}$ Epstein et al. also found that minority patients were substantially less likely to be treated at high-volume hospitals with reported lower mortality rates..$^{15}$ Disparities in access to specialized surgical care may additionally be part of the complex factors involved in this volume-outcome relationship. Future studies aimed at deciphering factors involved in outcome differences between high- and low-volume hospitals may consider factors such as differences in hospital referrals and in a patient's insurance and preferences.

In a technical review prepared by the UCSF-Stanford EPC for the AHRQ, it is reported that PSIs capture adverse events that may be related to medical care, but that also may be a result of other factors. ${ }^{29}$ For example, the ability of PSIs to differentiate between preexisting conditions and those acquired during hospital admission remains open to debate. ${ }^{5}$ As Bahl et al. reported, the rate of PSI occurrence in their cohort decreased on inclusion of a "present on admission" variable. This variable accounts for conditions that were present at admission, therefore minimizing false positives in reported PSI occurrence rates. Once patients' condition on admission was corrected for, the rates of a subset of PSIs were significantly reduced.

Although this study is limited by our inability to determine when a PSI occurred, a thorough inclusion of specific postsurgical PSIs and the confirmation that a procedure giving rise to a PSI occurred within the index hospital stay gives validity to the assertion that these condi- 
tions occurred during the hospitalization of interest rather than as preexisting conditions. As with any retrospective administrative database study, there are several strengths and inherent limitations. ${ }^{3,4,14,24,36}$ In our study we adjusted for preexisting comorbidities by calculating the Elixhauser index score, yet we recognize that the reliability of this metric is strongly dependent on comprehensive documentation. Although we conjectured on several possibilities for the volume-outcome association, our study, similar to other national cohorts, was unable to identify the precise factors driving this interaction. A major strength of this study was our ability to assess PSIs and HACs across a wide variety of hospitals nationwide.

Quality indicators such as PSIs, HACs, and in-hospital mortality were developed with the goal of reflecting quality of care based on hospital administrative data that are collected as a standard effort of health care delivery (AHRQ). Our study showed that hospitals with a higher volume of craniotomies also had lower mortality, PSI, and HAC rates. However, caution must be exercised when generalizing this association of hospital performance to one of quality of care. High-volume, high-performance hospitals may not necessarily correspond to hospitals providing the highest quality of surgical care. The Institute of Medicine has defined quality of health care as "the degree to which health services for individuals and populations increase the likelihood of desired health outcomes and are consistent with current professional knowledge." 23 Therefore, the definition of quality of care is two-sided, because it relies on both the demonstration of superior outcomes as well as adherence to current standards for quality of care. Because this study queried patients from the NIS, an administrative database, we did not have access to data regarding the quality of care. Therefore, due to this limitation, we are only able to comment on the performance of hospitals by volume in terms of these established metrics, rather than the quality of care provided.

\section{Conclusions}

Patient safety-related adverse events were strongly associated with in-hospital mortality rates, whereas HACs were not. Moderate to strong correlations were found between PSI, HAC, and hospital procedural volume. Patients treated at the highest-volume hospitals had consistently lower rates of mortality, PSIs, and HACs compared with those treated at the lowest-volume facilities. In-hospital mortality, PSIs, and HACs all have been proposed as metrics of surgical quality. However, as per the dual definition of quality of care proposed by the Institute of Medicine, further work is required to establish a connection between performance metrics and the quality of surgical care in this patient population.

\section{Acknowledgment}

This work was supported in part through funding from an American Medical Association Seed Grant and a grant from The Robert Wood Johnson Foundation.

\section{References}

1. Agency for Healthcare Research and Quality: Guide to In- patient Quality Indicators: Quality of Care in HospitalsVolume, Mortality, and Utilization. Rockville: Department of Health and Human Services, Agency for Healthcare Research and Quality, 2002

2. Agency for Healthcare Research and Quality: Healthcare Cost and Utilization Project Databases: Nationwide Inpatient Sample. (http://www.hcup-us.ahrq.gov/nisoverview.jsp) [Accessed March 27, 2015]

3. Amin BY, Tu TH, Schairer WW, Na L, Takemoto S, Berven $\mathrm{S}$, et al: Pitfalls of calculating hospital readmission rates based on nonvalidated administrative data sets. Clinical article. J Neurosurg Spine 18:134-138, 2013

4. Aronsky D, Haug PJ, Lagor C, Dean NC: Accuracy of administrative data for identifying patients with pneumonia. Am J Med Qual 20:319-328, 2005

5. Bahl V, Thompson MA, Kau TY, Hu HM, Campbell DA Jr: Do the AHRQ patient safety indicators flag conditions that are present at the time of hospital admission? Med Care 46:516-522, 2008

6. Betka J, Zvěřina E, Balogová Z, Profant O, Skřivan J, Kraus $\mathrm{J}$, et al: Complications of microsurgery of vestibular schwannoma. Biomed Res Int 2014:315952, 2014

7. Bianco FJ Jr, Riedel ER, Begg CB, Kattan MW, Scardino PT: Variations among high volume surgeons in the rate of complications after radical prostatectomy: further evidence that technique matters. J Urol 173:2099-2103, 2005

8. Birkmeyer JD, Siewers AE, Finlayson EV, Stukel TA, Lucas FL, Batista I, et al: Hospital volume and surgical mortality in the United States. N Engl J Med 346:1128-1137, 2002

9. Birkmeyer JD, Skinner JS, Wennberg DE: Will volume-based referral strategies reduce costs or just save lives? Health Aff (Millwood) 21:234-241, 2002

10. Centers for Medicare and Medicaid Services: Hospitalacquired conditions. (http://www.cms.gov/Medicare/ Medicare-Fee-for-Service-Payment/HospitalAcqCond/ Hospital-Acquired_Conditions.html) [Accessed March 30, 2015]

11. Charlson ME, Pompei P, Ales KL, MacKenzie CR: A new method of classifying prognostic comorbidity in longitudinal studies: development and validation. J Chronic Dis 40: 373-383, 1987

12. Darrouzet V, Martel J, Enée V, Bébéar JP, Guérin J: Vestibular schwannoma surgery outcomes: our multidisciplinary experience in 400 cases over 17 years. Laryngoscope 114:681-688, 2004

13. Department of Health and Human Services: ICD-9-CM Official Guidelines for Coding and Reporting. (http://www. cdc.gov/nchs/data/icd/icd9cm_guidelines_2011.pdf) [Accessed March 30, 2015]

14. Elixhauser A, Steiner C, Harris DR, Coffey RM: Comorbidity measures for use with administrative data. Med Care 36:8-27, 1998

15. Epstein AJ, Gray BH, Schlesinger M: Racial and ethnic differences in the use of high-volume hospitals and surgeons. Arch Surg 145:179-186, 2010

16. Fargen KM, Neal D, Rahman M, Hoh BL: The prevalence of patient safety indicators and hospital-acquired conditions in patients with ruptured cerebral aneurysms: establishing standard performance measures using the Nationwide Inpatient Sample database. J Neurosurg 119:1633-1640, 2013

17. Fargen KM, Rahman M, Neal D, Hoh BL: Prevalence of patient safety indicators and hospital-acquired conditions in those treated for unruptured cerebral aneurysms: establishing standard performance measures using the Nationwide Inpatient Sample database. J Neurosurg 119:966-973, 2013

18. Finks JF, Osborne NH, Birkmeyer JD: Trends in hospital volume and operative mortality for high-risk surgery. $\mathbf{N}$ Engl J Med 364:2128-2137, 2011

19. Finlayson EV, Goodney PP, Birkmeyer JD: Hospital volume 
and operative mortality in cancer surgery: a national study. Arch Surg 138:721-726, 2003

20. Ghaferi AA, Birkmeyer JD, Dimick JB: Hospital volume and failure to rescue with high-risk surgery. Med Care 49:10761081, 2011

21. Goodney PP, Stukel TA, Lucas FL, Finlayson EV, Birkmeyer JD: Hospital volume, length of stay, and readmission rates in high-risk surgery. Ann Surg 238:161-167, 2003

22. Gutierrez JC, Perez EA, Moffat FL, Livingstone AS, Franceschi D, Koniaris LG: Should soft tissue sarcomas be treated at high-volume centers? An analysis of 4205 patients. Ann Surg 245:952-958, 2007

23. Institute of Medicine: Medicare: A Strategy for Quality Assurance. Washington, DC: National Academy Press, 1990, Vol 1

24. Jhung MA, Banerjee SN: Administrative coding data and health care-associated infections. Clin Infect Dis 49:949_ 955,2009

25. Lassen B, Helseth E, Rønning P, Scheie D, Johannesen TB, Mæhlen J, et al: Surgical mortality at 30 days and complications leading to recraniotomy in 2630 consecutive craniotomies for intracranial tumors. Neurosurgery 68:1259-1269, 2011

26. Lee SL, Yaghoubian A, Stark R, Shekherdimian S: Equal access to healthcare does not eliminate disparities in the management of adults with appendicitis. J Surg Res 170:209213,2011

27. Luft HS, Bunker JP, Enthoven AC: Should operations be regionalized? The empirical relation between surgical volume and mortality. N Engl J Med 301:1364-1369, 1979

28. Marras LC, Geerts WH, Perry JR: The risk of venous thromboembolism is increased throughout the course of malignant glioma: an evidence-based review. Cancer 89:640-646, 2000

29. McDonald KM, Romano PS, Geppert J, Davies SM, Duncan BW, Shojania KG, et al: Measures of Patient Safety Based on Hospital Administrative Data-The Patient Safety Indicators. Rockville: Agency for Healthcare Research and Quality, Department of Health and Human Services, 2002

30. Mukherjee D, Kosztowski T, Zaidi HA, Jallo G, Carson BS, Chang DC, et al: Disparities in access to pediatric neurooncological surgery in the United States. Pediatrics 124:e688e696, 2009

31. Mukherjee D, Zaidi HA, Kosztowski T, Chaichana KL, Brem $\mathrm{H}$, Chang DC, et al: Disparities in access to neuro-oncologic care in the United States. Arch Surg 145:247-253, 2010
32. Ogura K, Yasunaga H, Horiguchi H, Ohe K, Shinoda Y, Tanaka S, et al: Impact of hospital volume on postoperative complications and in-hospital mortality after musculoskeletal tumor surgery: analysis of a national administrative database. J Bone Joint Surg Am 95:1684-1691, 2013

33. Palmer JD, Sparrow OC, Iannotti F: Postoperative hematoma: a 5-year survey and identification of avoidable risk factors. Neurosurgery 35:1061-1065, 1994

34. Rahman M, Neal D, Fargen KM, Hoh BL: Establishing standard performance measures for adult brain tumor patients: a Nationwide Inpatient Sample database study. Neuro Oncol 15:1580-1588, 2013

35. Ross JS, Normand SL, Wang Y, Ko DT, Chen J, Drye EE, et al: Hospital volume and 30-day mortality for three common medical conditions. N Engl J Med 362:1110-1118, 2010

36. Sarrazin MS, Rosenthal GE: Finding pure and simple truths with administrative data. JAMA 307:1433-1435, 2012

37. Tsai TC, Joynt KE, Orav EJ, Gawande AA, Jha AK: Variation in surgical-readmission rates and quality of hospital care. N Engl J Med 369:1134-1142, 2013

38. Zacharia BE, Deibert C, Gupta G, Hershman D, Neugut AI, Bruce JN, et al: Incidence, cost, and mortality associated with hospital-acquired conditions after resection of cranial neoplasms. Neurosurgery 74:638-647, 2014

\section{Author Contributions}

Conception and design: Nuño, Mukherjee, Patil. Acquisition of data: Nuño. Analysis and interpretation of data: Nuño. Drafting the article: Nuño, Carico. Critically revising the article: all authors. Reviewed submitted version of manuscript: Carico, Black, Patil. Approved the final version of the manuscript on behalf of all authors: Nuño. Statistical analysis: Nuño. Administrative/technical/material support: Nuño. Study supervision: Nuño.

\section{Correspondence}

Miriam Nuño, Center for Neurosurgical Outcomes Research, Department of Neurosurgery, Cedars-Sinai Medical Center, Advanced Health Sciences Pavilion, 127 S. San Vicente Blvd., Suite A6229, Los Angeles, CA 90048. email: miriam.nuno@cshs. org. 